\title{
Comparison of the incidence of sibling cannibalism between male-killing Spiroplasma infected and uninfected clutches of a predatory ladybird beetle, Harmonia axyridis (Coleoptera: Coccinellidae)
}

\author{
Kayo NAKamurA ${ }^{1}$, Kazuki MiURA ${ }^{1,2}$ Peter de JONG ${ }^{3}$ and Hideki UENO ${ }^{4}$ \\ ${ }^{1}$ Laboratory of Management of Environmental Dynamics, Graduate School of Biosphere Sciences, Hiroshima University, \\ Higashi-Hiroshima 739-8528, Japan; e-mail: knakamur@affrc.go.jp \\ ${ }^{2}$ National Agricultural Research Center for Western Region, Fukuyama 721-8514, Japan \\ ${ }^{3}$ Laboratory of Entomology, Wageningen University, PO Box 8031, 6700 EH Wageningen, The Netherlands \\ ${ }^{4}$ Laboratory of Biology, Faculty of Education and Human Sciences, Niigata University, Niigata 950-2181, Japan
}

Key words. Sibling cannibalism, Coccinellidae, Spiroplasma, Harmonia axyridis, male-killing microorganism, hatching rate, ladybird beetle

\begin{abstract}
The incidence of sibling cannibalism in clutches of Harmonia axyridis infected by the male-killing Spiroplasma was compared with that in uninfected clutches, and the way in which fitness compensation was realized by sibling cannibalism was investigated. Primarily the rate of sibling cannibalism was determined by the hatching rate as all unviable eggs were consumed both in infected and uninfected clutches. Per capita consumption of roughly 0.1 individuals was estimated for uninfected clutches in the present study, as compared to 0.3 individuals in previous studies. The per capita consumption in infected clutches was 1.4, showing that the male-killing behavior of the Spiroplasma provides an approximately 4-14 fold increase in the chance of sibling cannibalism. Both in infected and uninfected clutches, the median of the starting time of sibling cannibalism was soon after that of the completion of hatching. Larvae started to disperse from their egg clutches only about $7.5-8.5 \mathrm{~h}$ after the initiation of hatching. These time sequences indicate that sibling cannibalism occurs at the earlier stage of the hatching process and the density of aphids in the area has little or no influence on incidence of the sibling cannibalism. During the maintenance of the infected line for five generations, exclusively females were produced and the median of the hatching rate was 0.395 , suggesting a very high rate of vertical transmission of the Spiroplasma infection. Although the measurement of other parameters, such as the effect of Spiroplasma infection on fecundity or longevity, are necessary, the high compensation rate shown in the present study, together with the very high vertical transmission, may explain the prevalence of the present male-killing agent in the local populations of the ladybird beetle.
\end{abstract}

\section{INTRODUCTION}

Cannibalism among sibling members at the initial developmental stage has been documented in various groups of insects and regarded as an important survival tactic (Elgar \& Crespi, 1992). A high incidence of sibling cannibalism is observed in predatory ladybird beetles (Kawai, 1978; Osawa, 1989; Majerus \& Hurst, 1997; Dixon, 2000). The phenomenon has been viewed as the redeployment of resources. Unviable eggs in egg clutches of the predatory ladybird species have been regarded as "tropic eggs", where maternal investment is redistributed among the siblings (Stevens, 1992; Dixon, 2000). The selective advantage to cannibalism increases as the benefit to the cannibal increases or the cost to the victim or relatedness decreases (Hamilton, 1964a, b). Estimation of the inclusive fitness consequence of sibling cannibalism in the predatory ladybird beetle, Harmonia axyridis (Pallas), suggests that especially under poor nutritional conditions, cannibalism is favored both from cannibal's and their full-sib victim's point of view, and the female's fitness does not change regardless of the intensity of sibling cannibalism (Osawa, 1992).

The view to regard unviable eggs as nutritional investment provided by the female has been changed by the recent findings of different male-killing microorganisms from various species of ladybird beetles (Hurst et al., 1992; Zakharov et al., 1999; Majerus \& Majerus, 2000; Schulenburg et al., 2001). These cytoplasmically inherited microorganisms are transmitted vertically through the female lines and kill male progenies carrying them, resulting in the reduction of hatching rate to around $50 \%$. Sibling females, which carry clonal relatives of the microorganisms, are supposed to have nutritional gain from the sibling cannibalism. As fitness consequence of the malekilling microorganism depends on that of the host females, natural selection will favor the microorganism tendency of killing male progeny, through which the microorganism cannot pass and therefore has a fitness cost of zero from its point of view.

The evolutionary dynamics of the male-killing microorganisms have received theoretical considerations, and the degree of fitness compensation, the additional fitness gain to the infected females accrued by sibling cannibalism, is a critical parameter that determines the criteria of invasion of male-killing microorganisms to a host population (Hurst, 1991). However, there has been no empirical study that estimates whether and how the fitness compensation is influenced by the male-killing. The present study compared the incidence of sibling cannibalism in clutches of Harmonia axyridis infected by the male-killing Spiro- 
plasma with that in uninfected clutches, and the significance of the fitness compensation to the evolution of male-killing behavior of the microorganism is discussed.

\section{MATERIAL AND METHODS}

Harmonia axyridis overwinters at the adult stage, and starts oviposition in the spring. Pupae were collected in May and June 2001 from Muikamachi, Niigata, Japan. They were kept individually in Petri dishes at $20^{\circ} \mathrm{C}$ and a photoperiod of $16 \mathrm{~L}: 8 \mathrm{D}$. These rearing conditions were maintained throughout the experiment. Emerged adults were provided with pea aphids, Acyrthosiphon pisum, as food. Sex of the emerged adults was identified and males and females were paired. After copulation, each female was kept individually and egg clutches were checked daily. When egg clutches were found, the female was transferred to a new Petri dish. The eggs were counted and the hatching rate was recorded. Larvae were reared individually to adulthood under the same conditions and their sex ratio was recorded.

The field collected females were regarded as infected with male-killing microorganisms when the hatching rate of their egg clutches was below $70 \%$ and only female progeny was obtained. These family lines were tested for the presence of male-killing microorganisms, by performing PCR amplification and sequencing. First, DNA was extracted from a single adult ovarium which was crushed with a needle in $30 \mu \mathrm{l}$ of a Tris-EDTA buffer [5N NaCl, 500nM EDTA (pH 8.0), 1M Tris-HCl (pH8.0)] and $5 \%$ Chelex ${ }^{\mathrm{R}}(\mathrm{Bio}-\mathrm{Rad})$, and incubated with proteinase $\mathrm{K}(20$ $\mathrm{mg} / \mathrm{ml}$ ) at $56^{\circ} \mathrm{C}$ for $3 \mathrm{~h}$. Each DNA sample was analyzed for bacterial presence through a PCR reaction using general bacterial 16SrDNA primers (Weisburg et al., 1991). Primers 27f (5'-GAG AGT TTG ATC CTG GCT CAG-3') and 1495r (5'-CTA CGG CTA CCT TGT TAC GA-3') were used in $33 \mu \mathrm{l}$ reactions containing, 1.5 units Taq polymerase (PE Applied Biosystems), $3.3 \mu 12 \mathrm{nM}$ dNTPmix, $400 \mathrm{nM}$ forward and reverse primer, $3.3 \mu 110 \times$ PCR buffer, $3.3 \mu 1125 \mathrm{nM} \mathrm{MgCl}_{2}, 1$ $\mu 1$ DNA template and $20.3 \mu 1$ sterile water. Temperature cycling was carried out in an ABI thermal cycler (PE Applied Biosystems PCR System 9700 and 2400) as follows: $10 \mathrm{~min}$ at $95^{\circ} \mathrm{C}$, 35 cycles for $30 \mathrm{~s}$ at $95^{\circ} \mathrm{C}, 30 \mathrm{~s}$ at $55^{\circ} \mathrm{C}, 2 \mathrm{~min}$ at $72^{\circ} \mathrm{C}$, and 2 min at $72^{\circ} \mathrm{C}$. Successful amplification was determined by electrophoresing $3 \mu 1$ of PCR reaction on $2 \%$ agarose gel $(1 \times \mathrm{TAE})$, stained with ethidium bromide, and observed under an UV transilluminator. Samples of PCR with the 16SrDNA primers that yielded amplicons of the expected size were cloned by using p-GEMT Easy Vector system (Promega). Plasmids were amplified, purified, and sequenced. Subsequently to determine if Spiroplasma is present we used Spiroplasma-specific primers. The primers used were SP-ITS-JO4 (5'-GCC AGA AGT CAG TGT CCT AAC CG-3') and SP-ITS-N55 (5'-GCG TAT GGT GGA TGC CTT GGA AT-3') which were designed to span the spacer region between the 16S and 23S rRNA genes (Schulenburg et al., unpubl.). Temperature cycling was carried out in an ABI thermal cycler as follows: $10 \mathrm{~min}$ at $95^{\circ} \mathrm{C}, 35$ cycles for $30 \mathrm{~s}$ at $95^{\circ} \mathrm{C}, 30 \mathrm{~s}$ at $55^{\circ} \mathrm{C}, 2 \mathrm{~min}$ at $72^{\circ} \mathrm{C}$, and $2 \mathrm{~min}$ at $72^{\circ} \mathrm{C}$. Successful amplification was determined by electrophoresing $3 \mu \mathrm{l}$ of PCR reaction on $2 \%$ agarose gel $(1 \times \mathrm{TAE})$, stained with ethidium bromide, and observed under an UV transilluminator.

Second, when the 16SrDNA sequence was compared with other known sequences using an advanced BLAST (National Center for Biotechnology Information) search, all closest matches were bacteria affiliated with Spiroplasma. Methods of detection for BLAST search are provided in Nakamura et al. (2005). When subjected to a BLAST search (Altschul et al., 1990), these sequences showed a high homology to 16SrDNA of Group VI Spiroplasmas. We did not find any Rickettsia or Wolbachia. An uninfected line was also established from a field collected female that produced egg clutches of high hatching rate and progenies of both sexes in about equal numbers.

The infected and uninfected families were reared in the laboratory for four or five generations before the sibling cannibalism was observed. These families were maintained by crossing with field-collected males. For infected females, clutch sizes about twice as large as those of uninfected females were chosen, since hatching rate of infected clutches is only about $50 \%$. This ensured that the behavior of roughly the same number of siblings was observed for infected and uninfected clutches; thus the redistribution of unhatched sibling eggs may be influenced the number of hatched larvae. For each egg clutch, clutch size, number of cannibalized eggs and larvae, and larvae that were successful in hatching were recorded. Color of eggs was also recorded. Eggs remaining yellow at the time of hatching were regarded as not developing and those that turned grey were developing. Of each larva the time of hatching was recorded as well as its dispersal from the egg clutch. Cannibalism was defined as number of cannibalized eggs and larvae divided by the initial clutch size, thus the cannibalized larvae were counted both in hatching and cannibalism rate. The Mann-Whitney U test was used to compare the traits mentioned above between infected and uninfected clutches. Spearman rank correlation was calculated to detect the correlation between the proportion of grey eggs cannibalized and hatching duration.

\section{RESULTS}

The cannibalism rate was larger for infected than for uninfected clutches, and the difference was highly significant (Mann-Whitney $U$ test: $U=5, P<0.0001$ ). In infected clutches, the median of per capita consumption was 1.4 individuals while in uninfected clutches, it was 0.1 (Mann-Whitney $U$ test: $U=5, P<0.0001$ ). All yellowish eggs were cannibalized both in infected and uninfected clutches, which accounted for the largest portion of victims (Table 1). In infected clutches, the median hatching rate was $0.420\left(\mathrm{Q}_{3}-\mathrm{Q}_{1}=0.534-0.392, n=20\right)$ while in uninfected clutches, it was $0.905\left(\mathrm{Q}_{3}-\mathrm{Q}_{1}=\right.$ $0.960-0.818, n=19)$, and the difference was significant (Mann-Whitney $U$ test: $U=6, P<0.0001$ ). There was a highly significant relationship between the cannibalism and hatching rate both in infected $\left(r_{s}=-0.968, n=20, P\right.$ $<0.0001)$ and uninfected clutches $\left(r_{s}=-0.988, n=19, P\right.$ $<0.0001)$.

A significantly larger proportion of grey eggs was cannibalized in infected than uninfected clutches (MannWhitney $U$ test: $U=71.5, P=0.0087$ ) (Table 1). Cannibalism of hatching larvae accounted for a small portion of total cannibalism, and there was no difference in the proportion of hatching larvae cannibalized between infected and uninfected clutches (Mann-Whitney $U$ test: $U=187$, $P=0.933$ ).

There was no significant difference between infected and uninfected clutches in the time sequence of completion of hatching, start of sibling cannibalism and dispersal from the clutches (Fig. 1). Both in infected and uninfected clutches, the median of the starting time of sibling cannibalism was soon after that of the completion of hatching. In some cases, hatching larvae were observed to cannibalize the adjacent eggs even before the completion of 
TABLE 1. Incidence of sibling cannibalism in Spiroplasma infected (A) and uninfected (B) clutches. For an indicator of variation around the median, interquartile ranges are given in parentheses.

\begin{tabular}{lcccc}
\hline \multicolumn{1}{c}{ total } & yellow eggs & grey eggs & hatching larvae \\
\hline median of number of eggs or larvae per clutch & $29(44.3-24)$ & $12.5(16.8-6.3)$ & $15(26.3-9.3)$ & $13(16.8-7.3)$ \\
median of number of eggs or larvae cannibalized & $17(24.5-12)$ & $12.5(16.8-6.3)$ & $2(7.8-0.3)$ & $0(0-0)$ \\
median of sibling cannibalism rate & $0.580^{\mathrm{a}}(0.626-0.481)$ & $1.000(1.000-1.000)$ & $0.211^{\mathrm{b}}(0.356-0.017)$ & $0^{\mathrm{c}}(0-0)$ \\
\hline \multicolumn{1}{c}{$(\mathrm{B})$ uninfected clutches $(\mathrm{n}=19)$} & \multicolumn{5}{c}{} \\
\hline median of number of eggs or larvae per clutch & $19(23-13)$ & $1(4-0)$ & $18(22-12)$ & $17(22-10)$ \\
median of number of eggs or larvae cannibalized & $2(4-1)$ & $1(4-0)$ & $0(1-0)$ & $0(0-0)$ \\
median of sibling cannibalism rate & $0.095^{\mathrm{a}}(0.250-0.040)$ & $1.000(1.000-1.000)$ & $0^{\mathrm{b}}(0.043-0)$ & $0^{\mathrm{c}}(0-0)$ \\
\hline
\end{tabular}

Mann-Whitney $U$ test to compare sibling cannibalism rates in total, grey eggs and hatching larvae between infected and uninfected clutches. Sibling cannibalism rates of yellow eggs were not analyzed by Mann-Whitney $U$ test since cannibalism rates were 1.000 in all clutches. ${ }^{\mathrm{a}} P<0.001 ;{ }^{\mathrm{b}} P=0.0005 ;{ }^{\mathrm{c}} P=0.8923$.

their own hatching from the egg shells. Larvae started to disperse form their egg clutches, only about 7.5-8.5 h after the initiation of hatching, when all eggs were completely cannibalized.

In infected clutches, the proportion of grey eggs cannibalized was positively correlated with hatching duration ( $\left.r_{s}=0.530, n=17, P=0.0423\right)$. On the other hand, few of the grey eggs were cannibalized in uninfected clutches and no correlation was detected with hatching duration $\left(r_{s}\right.$ $=-0.217, n=17, P=0.4023$ ).

While the hatching duration itself is not different between infected and uninfected clutches, the synchronous nature of hatching is different in infected ones (Fig. 1). It is also possible that the infection of Spiroplasma causes half-developing grey eggs in clutches, which are still inviable and vulnerable to sibling cannibalism.

Reproduction of 15 different females observed during the maintenance of the infected line for five generations indicated that the median of the hatching rate was 0.395 $\left(\mathrm{Q}_{3}-\mathrm{Q}_{1}=0.514-0.218\right)$ and that no single male was produced out of 188 offspring in total.

\section{DISCUSSION}

Primarily the rate of sibling cannibalism was determined by the hatching rate as all unviable eggs were consumed both in infected and uninfected clutches. Sibling cannibalism in Harmonia axyridis accounted for about one fourth of egg losses in a field population (Osawa, 1989) and in a laboratory observation (Kawai, 1978), resulting in per capita consumption of roughly 0.3 . In the present study, the median of the per capita consumption was 0.1 for uninfected clutches. Comparing these estimates with per capita consumption of 1.4 in infected clutches, the male-killing behavior of the Spiroplasma provides approximately 4-14 fold increase in the chance of sibling cannibalism.

Since females of $H$. axyridis tend to oviposit egg clutches a slight distance away from aphid colonies to reduce the risk of non-sibling cannibalism (Osawa, 1989), the sibling cannibalism could lead to a significant fitness increase especially at the initial stage of development. For the present species, two studies reported the effects of the

\section{INFECTED CLUTCHES}

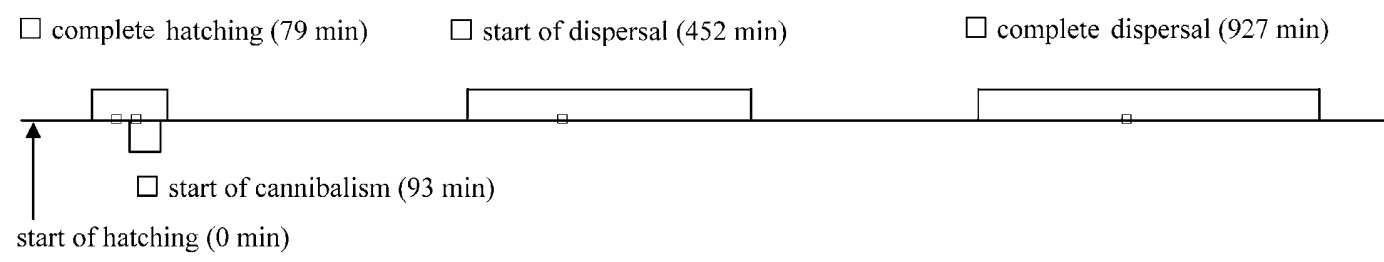

\section{UNINFECTED CLUTCHES}

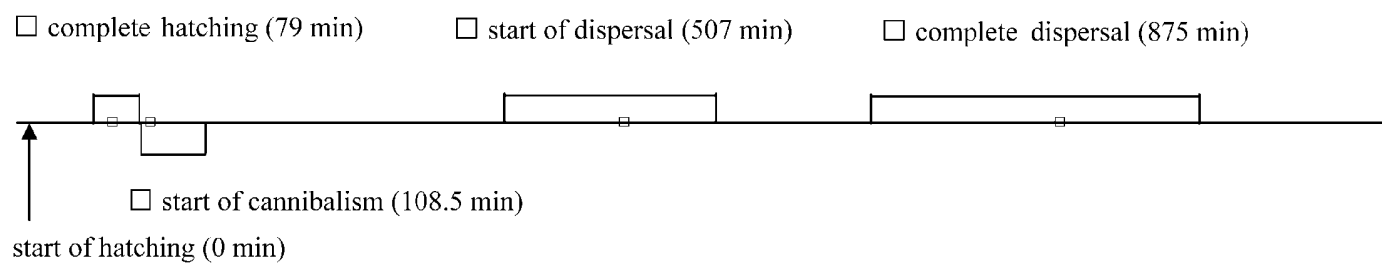

Fig. 1. The median of time sequence of hatching, sibling cannibalism and dispersal from infected and uninfected clutches. Bars represent interquartile ranges. There was no significant difference between infected and uninfected clutches in the time of completion of hatching (Mann-Whitney $U$ test: $U=122.5, P=0.850$ ), start of sibling cannibalism (Mann-Whitney $U$ test: $U=20, P=$ 0.124 ) and dispersal from the clutches (Mann-Whitney $U$ test: $U=103, P=0.708$ ). 
sibling cannibalism on fitness. Kawai (1978) found that the surviving time of first instar larvae became twice as long when one egg was cannibalized. Also, consumption of one, two or three eggs resulted in a significant increase of survivorship to the second instar at low aphid density; when no egg was taken, survivorship was only 0.124 , while consumption of one, two or three eggs resulted in $0.404,0.622$ and 0.778 survival, respectively (Osawa, 1992). Surviving rate to the second instar at low aphid density of infected larvae is 0.499 and uninfected one is 0.155 , when the number of cannibalized eggs of this study is substituted in Osawa's equation (1992). The first instar lavrae have difficulties capturing and eating aphids (Kawai, 1976) and the fitness consequence of the malekilling microorganism depends on that of the host females. Therefore sibling cannibalism is adaptive to male-killer on the life history of Harmonia axyridis.

The time sequences indicate that sibling cannibalism occurs at the earlier stage of the hatching process and the density of aphids in the area has little or no influence on the incidence of sibling cannibalism. There was no significant relationship between the sibling cannibalism rate and the direct distance from a clutch to the nearest aphid colony, albeit without distinction between infected and uninfected clutches, in the field (Osawa, 2003).

The recent findings of the Spiroplasma from different local populations of $H$. axyridis suggest that the infection of the present microorganism is common in Japan (Majerus et al., 1998, 1999; Majerus, 2001; Nakamura et al., 2005). The fitness compensation and vertical transmission rate are the two most critical parameters that determine the evolution of male-killing behavior (Hurst, 1991). For the Spiroplasma infection in a population of $H$. axyridis, a very high rate of vertical transmission was reported (Majerus et al., 1998). Also in the present study, the very high rate of vertical transmission for the Spiroplasma infection is supported. Although the measurement of other parameters, such as the effect of Spiroplasma infection on fecundity or longevity, are necessary, the high compensation rate shown in the present study, together with the very high vertical transmission, may explain the prevalence of the present male-killing agent in the local populations of the ladybird beetle. The possible effects of the Spiroplasma on the host beetles, especially under natural conditions, are of critical importance.

ACKNOWLEDGMENTS. This research is supported in part by a Japan Society for the Promotion of Science (JSPS).

\section{REFERENCES}

Altschul S.F., Gish W., Miller W., Meyers E.W. \& Lipman D.J. 1990: Basic local alignment search tool. J. Mol. Biol. 215: 403-410.

Dixon A.F.G. 2000: Insect Predator-Prey Dynamics. Ladybird Beetles and Biological Control. Cambridge University Press, Cambridge, ix $+257 \mathrm{pp}$.

Elgar M.A. \& CRespi B.J. 1992: Ecology and Evolution of Cannibalism. Cannibalism: Ecology and Evolution among Diverse Taxa. Oxford University Press, Oxford, 369 pp.

Hamilton W.D. 1964a: The genetical evolution of social behavior I. J. Theor. Biol. 7: 1-16.
Hamilton W.D. 1964b: The genetical evolution of social behavior II. J. Theor. Biol. 7: 17-52.

HuRsT L.D. 1991: The incidences and evolution of cytoplasmic male killers. Proc. R. Soc. London (B) 244: 91-99.

Hurst G.D.D., Majerus M.E.N. \& WalKer L.E. 1992: Cytoplasmic male killing elements in Adalia bipunctata (Linnaeus) (Coleoptera: Coccinellidae). Heredity 69: 84-91.

KAWAI A. 1976: Analysis of the aggregation behavior in the larvae of Harmonia axyridis Pallas (Coleoptera: Coccinellidae) to prey colony. Res. Popul. Ecol. 18: 123-134.

KawAI A. 1978: Sibling cannibalism in the first instar larvae of Harmonia axyridis Pallas (Coleoptera, Coccinelidae). Konty $\hat{u}$ 46: $14-19$.

Majerus M.E.N. \& Hurst G.D.D. 1997: Ladybirds as a model system for the study of male-killing symbionts. Entomophaga 42: $13-20$

Majerus M.E.N. \& Majerus T.M.O. 2000: Female-biased sex ratio due to male-killing in the Japanese ladybird Coccinula sinensis. Ecol. Entomol. 25: 234-238.

Majerus T.M.O. 2001: The Evolutionary Genetics of Malekilling in the Coccinellidae. Ph. D. thesis, University of Cambridge.

Majerus T.M.O., Majerus M.E.N., Knowles B., Wheeler J., Bertrand D., Kuznetzov V.N., Ueno H. \& Hurst G.D.D. 1998: Extreme variation in the prevalence of inherited malekilling microorganisms between three populations of Harmonia axyridis (Coleoptera: Coccinellidae). Heredity 81: 683-691.

Majerus T.M.O., Schulenburg J.H., Majerus M.E.N. \& Hurst G.D.D. 1999: Molecular identification of a male-killing agent in the ladybird Harmonia axyridis (Pallas) (Coleoptera: Coccinellidae). Insect Mol. Biol. 8: 551-555.

Nakamura K., Ueno H. \& Miura K. 2005: Prevalence of inherited male-killing microorganism in Japanese population of ladybird beetle Harmonia axyridis (Coleoptera: Coccinellidae). Ann. Entomol. Soc. Am. 98: 96-99.

Osawa N. 1989: Sibling and non-sibling cannibalism by larvae of a lady beetle Harmonia axyridis Pallas (Coleoptera: Coccinellidae) in the field. Res. Popul. Ecol. 31: 153-160.

Osawa N. 1992: Sibling cannibalism in the ladybird beetle Harmonia axyridis: fitness consequences for mother and offspring. Res. Popul. Ecol. 34: 45-55.

Osawa N. 2003: The influence of female oviposition strarategy on sibling cannibalism in the ladybird beetle Harmonia axyridis (Coleoptera: Coccinellidae). Eur. J. Entomol. 100: $43-48$.

Schulenburg J.H.G. v.D., Habig M., Sloggett J.J., Webberley K.M., Bertrand D., Hurst G.D.D. \& Majerus M.E.N. 2001: Incidence of male-killing Rickettia spp. ( $\alpha$-Proteobacteria) in the ten-spot ladybird beetle Adalia decempunctata L. (Coleoptera: Coccinellidae). Appl. Envir. Microbiol. 67: 270-277.

Stevens L. 1992: Cannibalism in beetles. In Elgar M.A. \& Crespi B.J. (eds): Ecology and Evolution of Cannibalism. Cannibalism: Ecology and Evolution among Diverse Taxa. Oxford University Press, Oxford, pp. 157-175.

Weisburg W.G., Barns S.M., Pelletier D.A. \& Lane D.J. 1991: 16S ribosomal DNA amplification for phylogenetic study. $J$. Bacteriol. 173: 697-703.

Zakharov I.A., Zinkevich N.S., Shaikevich E.V., Vysotskaya L.V., Dorzhu Ch.M. \& Majerus M.E.N. 1999: Sex ratio and male killing in Siberian populations of Harmonia axyridis Pall. Rus. J. Genet. 35: 653-657.

Received May 18, 2005; revised and accepted January 3, 2006 